\title{
O papel da rede social de apoio no tratamento de adultos com câncer
}

\author{
Bárbara Albasini Bard* \\ Débora Staub Cano**
}

\begin{abstract}
Resumo
O câncer é um problema de saúde pública e a rede social de apoio é uma das principais fontes de suporte aos pacientes. Entende-se rede social como uma "teia de relações" que interligam os indivíduos, fornecendo apoio significativo. O objetivo deste estudo foi caracterizar o papel da rede social de apoio de quatro mulheres que se encontravam no período do pós-tratamento de câncer. Para tal foram utilizados dois instrumentos: entrevista semiestruturada e Mapa Mínimo da rede social de apoio. Os resultados mostraram que a presença de uma rede social funcional, que se caracteriza como fornecedora de apoio é fundamental para o bem-estar de pacientes com câncer. Observou-se que o apoio aos pacientes por meio da rede social funcional em situações de crise, melhora a autoestima e a qualidade de vida desses pacientes, tornando o diagnóstico, o tratamento e o pós-tratamento um processo menos doloroso. Por outro lado, as redes sociais disfuncionais, que antes do tratamento já se caracterizavam por relações conflituosas e não ofereciam suporte adequado, pioraram a autoestima e a qualidade de vida destes pacientes.
\end{abstract}

Palavras-chaves: Câncer. Rede social de apoio.

\section{Abstract}

The cancer has been considered a public health issue and the social support network is seen as a major source of support to patients. Social network is a "web of relationships" that interconnects people providing meaningful support. The aim of this research was to mark the social support network role of four women who were in the period of pos-treatment of cancer. Two instruments were used to data collection: semi structured interview and Minimum Map of social support. The results showed that the presence of a functional social network, which is characterized as a supportive provider, is fundamental for the well-being of cancer patients. It was observed that support to patients through the functional social network in crisis situations improves the self-esteem and quality of life of these patients, making diagnosis, treatment and post-treatment a less painful process. On the other hand, dysfunctional social network, which before the treatment were already characterized by conflicting relationships and did not offer adequate support, worsened the self-esteem and quality of life of these patients.

Keywords: Cancer. Social support network.

* Psicóloga pelas Faculdades Integradas de Taquara - FACCAT/RS. E-mail: barbara.albasini@gmail.com.

** Mestre em psicologia e Professora do Curso de Psicologia das Faculdades Integradas de Taquara - FACCAT/RS. 


\section{Introdução}

A denominação câncer é utilizada para nomear mais de 100 doenças, que têm como denominador comum o crescimento desordenado de células. Os diferentes tipos de câncer estão associados à velocidade de multiplicação e a capacidade de invadir tecidos e órgãos vizinhos ou distantes - metástase (Inca, 2015). As células que se encontram fora do padrão normal de divisão celular do tecido originário são denominadas neoplasma ou tumor (Borges-Osório \& Robinson, 2002).

Os tumores são classificados em benignos ou malignos. Os primeiros são auto limitantes e não formam metástases, mas podem causar problemas por pressão mecânica. Os malignos apresentam crescimento ilimitado, podendo se disseminar para tecidos vizinhos e, também, por metástases, algumas células neoplásicas, desencadeiam um novo foco tumoral. A capacidade de metástase e a drenagem de nutrientes podem resultar na caquexia (emagrecimento exagerado), perda de funções vitais dos tecidos invadidos e na morte dos indivíduos (Borges-Osório \& Robinson, 2002).

Desde 2003, no Brasil, o câncer constitui a segunda maior causa de morte na população adulta, sendo considerado um problema de saúde pública, atingindo indivíduos de ambos os sexos, de todas as idades e classes sociais (Salci \& Marcon, 2011). A experiência de confirmação do câncer é um fator desencadeador de questionamentos e sofrimento (Monte, Soares, Portela, Pedrosa, Gomes \& Filho, 2015), sendo a depressão o transtorno psiquiátrico mais comum, com prevalências variando de $22 \%$ a $29 \%$ (Bottino, Fraguas \& Gattaz, 2009).

A vivência do câncer e dos seus diferentes estágios de tratamento traz repercussões físicas, psicológicas e sociais diversas e exige dos pacientes capacidade de adaptação e enfrentamento (Elmescany, 2010). Um dos fatores que auxilia o enfrentamento é a presença de uma rede social de apoio funcional (Cavini \& Gaspar, 2013). Entende-se por funcional uma rede social que seja estável, sensível, ativa e confiável (Sluzki, 1997), na qual os membros da rede prestam apoio com o objetivo de influenciar positivamente a saúde do paciente (Rodrigues \& Ferreira, 2012). Enquanto, uma rede social disfuncional possui um suporte emocional ineficaz, não oferecendo apoio suficiente, ao indivíduo (Santana, Zanin \& Maniglia, 2008). Caracterizando-se, geralmente, como relações conflituosas.

Embora, sejam utilizados com frequência, como sinônimos, rede social e apoio social são conceitos diferentes que estão relacionados entre si (Rodrigues \& Ferreira, 2012; Santana, Zanin \& Maniglia, 2008). Rede social refere-se a uma dimensão estrutural e institucional, pode ser formada pela família, pela vizinhança, pelos amigos ou organizações religiosas e sistema de saúde. Ela pode ser compreendida como uma 'teia de relações', que interligam os indivíduos que possuem vínculos e a partir destes vínculos ocorrem os apoios sociais (Sanchez, Ferreira, Dupas \& Costa, 2010).

O apoio social, portanto, possui uma dimensão informativa ou de recursos que serão fornecidos por membros da rede social, que podem gerar efeitos físicos, emocionais e comportamentais benéficos para o indivíduo e o seu grupo (Sanchez, Ferreira, Dupas \& Costa, 2010). O apoio social pode ser visto como uma relação de troca e de envolvimento entre quem presta apoio e quem recebe apoio. Trata-se de uma relação de reciprocidade, uma ajuda mútua que pode ser significativa, ou não, dependendo do grau de integração da rede (Lacerda, 2010; Leonidas, 2012).

De modo geral, com base nos achados da literatura (Andrade \& Vaistman, 2002; Cavini \& Gaspar, 2013; Sanchez, Ferreira, Dupas \& Costa, 2010; Ibiapina, Maia, Silva, Fernandes, Filho \& Fernandes, 2015; Rodrigues \& Ferreira, 2012; Santana, Zanin \& Maniglia, 2008; Sluzki, 1997) é possível perceber que a rede social de apoio funcional se mostra indispensável a todos os indivíduos, principalmente, em momentos de crise, como estes que são vivenciados pelos pacientes com câncer. Melhorando, assim, a qualidade de vida destes pacientes, aumentando a autoestima e, diminuindo os sentimentos de medo e insegurança.

Desta forma, a identificação das redes sociais significativas para o paciente, durante o tratamento, pode servir para instrumentalizar os profissionais, proporcionando um melhor direcionamento de ações e cuidados destinados à família e ao paciente hospitalizado (Menezes, Moré \& Barros, 2015). Assim, o presente estudo teve como objetivo caracterizar o papel da rede social de apoio no tratamento de adultos com câncer, visando identificá-la, antes, durante e após o diagnóstico. Pois, entende-se que reconhecer a família do adulto com câncer, como sujeito ativo no cuidado, torna-se essencial para o planejamento das intervenções durante o processo de adoecimento (Rodrigues \& Ferreira, 2012).

\section{Método}

\section{Delineamento}

O presente estudo caracteriza-se como qualitativo, de cunho exploratório, uma vez que, visa explorar e 
compreender o significado que os indivíduos atribuem a um problema social (Creswell, 2010), especificamente, as redes sociais de apoio de pacientes com câncer. Sendo, portanto, exploratório, na medida em que a investigação proporciona ao pesquisador se familiarizar com um determinado fenômeno (Marconi \& Lakatos, 2009).

\section{Participantes}

Participaram desta pesquisa quatro mulheres, com idades entre 52 e 70 anos, sendo três aposentadas e uma auxiliar de cozinha. Com relação ao estado civil, duas entrevistadas eram casadas e duas viúvas. Todas faziam parte de um grupo de apoio para pacientes com câncer promovido pela Vigilância Sanitária de um município da Região das Hortênsias, vinculadas ao Sistema Único de Saúde - SUS. Este foi um critério utilizado para a inclusão das participantes na pesquisa.

Entre as participantes, três foram diagnosticadas com câncer de mama e uma com câncer de esôfago. Todas as participantes estavam no período do pós-tratamento, sendo que dentre os tratamentos realizados estavam: cirurgia, quimioterapia e radioterapia. O tempo de descoberta da doença até o dia da aplicação dos instrumentos variou de um ano até seis anos. Além disto, entre as participantes, uma estava realizando exames para verificar uma possível metástase da doença.

Cabe apontar que, optou-se por trabalhar com pessoas que já estivessem em fase de manutenção do tratamento, visando evitar momentos críticos, que pudessem mobilizar emocionalmente as participantes. Para tanto, foram excluídos da pesquisa os indivíduos que estivessem iniciando seu tratamento oncológico, bem como, pacientes hospitalizados ou que estivessem em fase terminal da doença.

\section{Instrumentos}

Para a coleta de dados desta pesquisa, foram utilizados dois instrumentos, sendo eles: entrevista semiestruturada e Mapa mínimo da rede social de apoio (Sluzki, 1997).

\section{Entrevista semiestruturada}

A entrevista semiestruturada consiste em "uma série de perguntas abertas, feitas verbalmente em uma ordem prevista na qual o entrevistador pode acrescentar perguntas de esclarecimento" (Laville \& Dione, 1999, p.188), ou retirar alguma pergunta que já tenha sido contemplada em falas anteriores. Sendo, portanto, um instrumento de pesquisa com roteiro flexível, o que permite ao participante expor aspectos de sua experiência. Assim, a entrevista semiestruturada, elaborada, especialmente, para esta pesquisa, abordou quatro tópicos, que se desdobraram em perguntas especificas: 1) questões pessoais e sociais; 2) a doença, o diagnóstico e o tratamento; 3 ) a rede social de apoio antes do diagnóstico; 4) as redes sociais de apoio, após o diagnóstico e no momento atual de vida da participante.

\section{Mapa mínimo da rede social de apoio}

O Mapa mínimo da rede social de apoio (Figura 1.), instrumento proposto por Sluzki (1997), com o objetivo de registrar, em forma de mapa, todos os indivíduos com quem interage uma determinada pessoa. É composto por quatro quadrantes, que se referem à composição da rede, podendo ser composta, portanto, pela família, pelos amigos, pela comunidade e, pelo trabalho e/ou estudo. Além disto, o mapa possui três círculos que compreendem a distribuição dos membros da rede. Os vínculos da rede podem estar distribuídos em relações íntimas, sociais ou de conhecidos. Assim, o conjunto de indivíduos citados no mapa constitui a rede social das entrevistadas.

Figura 1 - Mapa mínimo da rede social de apoio

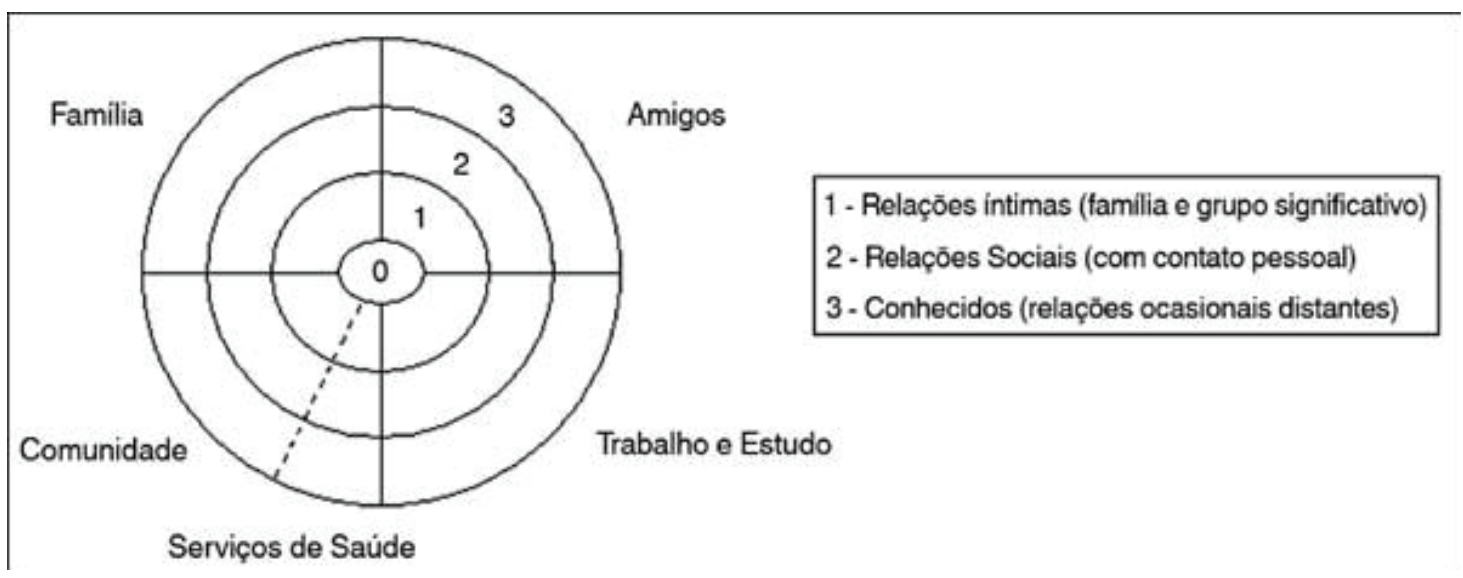


Desta forma, a aplicação do mapa prevê que se solicite ao participante, que inclua em cada quadrante indivíduos de seu grupo familiar, amigos, trabalho e/ou escola e, da comunidade, já informando e situando as pessoas em cada um dos círculos, de acordo com o grau de proximidade. Assim, vai sendo construído o mapa de relacionamentos interpessoais do sujeito, com dados sobre a estrutura da rede (tamanho, composição, distribuição, densidade, dispersão, homogeneidade e heterogeneidade). Após esse mapeamento, se solicita ao participante que explique as funções da rede (companhia social; apoio emocional; guia cognitivo e conselhos; regulação social; ajuda material e de serviços; e, acesso a novos contatos), para saber em que situações a participante recorre a cada uma das pessoas indicadas.

\section{Procedimentos Éticos e Coleta de dados}

A pesquisa atende aos princípios éticos dispostos nas Resoluções 510/2016, do Conselho Nacional de Saúde e 016/2000 do Conselho Federal de Psicologia para pesquisas com seres humanos. Para tanto, a pesquisa foi submetida ao Comitê de Ética da Instituição de Ensino FACCAT e foi aprovada com o n ${ }^{\circ} 1074$.

A coleta de dados ocorreu de agosto a setembro de 2016, por intermédio da Vigilância Sanitária de um município da Região das Hortênsias, uma vez que as participantes faziam parte de um grupo de apoio para pacientes oncológicos, realizado e coordenado por esta Instituição. Foi feito contato com o local para autorização formal para acessar ao grupo. Após, foi realizada uma visita ao grupo para apresentar a pesquisa aos possíveis participantes.

Os instrumentos foram aplicados em uma sala que é utilizada pela psicóloga da instituição. O horário e dia foram agendados a partir da disponibilidade das participantes. No dia e local combinado a pesquisadora procedeu à leitura do Termo de Consentimento Livre e Esclarecido (TCLE) para que as participantes formalizassem suas participações, estivessem cientes de como o processo ocorreria e permitissem a gravação em áudio da aplicação dos instrumentos. Após, foi realizada a entrevista e por último foi elaborado o Mapa mínimo da rede social.

\section{Análise dos dados}

Os dados obtidos na entrevista foram analisados a partir da análise de conteúdos qualitativos proposto por Laville e Dionne (1999). Os autores propõem que os conteúdos obtidos na pesquisa devem ser recortados e organizados dentro de categorias. Além disto, o presente estudo segue o modelo aberto, em que a construção das categorias foi realizada a posteriori, sendo construídas ao longo do processo de análise dos dados.

Com relação aos dados obtidos no Mapa mínimo da rede social, estes foram analisados conforme as categorias propostas por Sluzki (1997): Estrutura (tamanho, composição e distribuição, densidade e dispersão, homogeneidade e heterogeneidade) e Funções da rede (companhia social; apoio emocional; guia cognitivo e conselhos; ajuda material e de serviços).

\section{Resultados e Discussão}

A presente discussão será dividida em dois momentos, primeiramente será apresentado o Mapa mínimo da rede social de apoio, com questões acerca da estrutura e das funções da rede ${ }^{1}$. E, posteriormente, serão expostas as três categorias de análise, advindas dos relatos de entrevista: a) Rede social de apoio positiva; b) Rede social de apoio negativa; c) Mudanças após o tratamento.

\section{Mapa mínimo}

Os resultados obtidos na aplicação do Mapa mínimo serão apresentados em dois tópicos, com informações sobre: a) estrutura da rede e, b) funções da rede.

\section{Estrutura da rede}

Com relação ao tamanho da rede social de apoio houve uma variação de sete membros a 22 membros na rede. Portanto, conforme descrito na literatura (Leonidas \& Santos, 2013; Sluzki, 1997), nesta pesquisa, a participante E4 possui uma rede social considerada média, pois, sua rede possuía de sete a 10 membros, enquanto as outras três participantes (E1, E2, E3) possuíam uma rede de tamanho grande, formada por mais de 11 membros.

Os dados possibilitaram observar que, apesar, das redes serem consideradas médias (E4) ou grandes (E2), não contribuíram ou não eram efetivas no apoio, para estas duas entrevistadas, podendo assim, serem consideradas redes negativas. Apesar da quantidade média ou elevada de membros nas redes, boa parte deles pode não exercer papel significativo na vida das participantes (Leonidas \& Santos, 2013). O indivíduo, portanto, pode ter uma rede social e não receber, necessariamente, apoio desta rede (Santana, Zanin \& Maniglia, 2008).

Com relação à distribuição (Tabela 1.) dos membros da rede, obteve-se como resultado uma variação de duas a 16 pessoas citadas no quadrante relações íntimas; nas relações sociais obteve-se uma variação de três a seis

\footnotetext{
A categoria funções da rede foi elaborada tanto a partir dos dados advindos
} da aplicação do Mapa mínimo, como dos relatos das entrevistas. 
membros citados e; as relações de conhecidos foram citadas de um a três membros. Desta forma, o quadrante com mais membros da rede social foi o quadrante das relações íntimas, sendo composto, principalmente, por membros da família. Seguido pelas relações sociais, composto por amigos, vizinhos, pela secretaria de saúde, grupos comunitários e alguns membros da família.

Tabela 1 - Distribuição da rede social de apoio

\begin{tabular}{l|l|l|l}
\hline Participantes & $\begin{array}{l}\text { Relações } \\
\text { íntimas }\end{array}$ & $\begin{array}{l}\text { Relações } \\
\text { sociais }\end{array}$ & Conhecidos \\
\hline E1 & 04 & 06 & 01 \\
\hline E2 & 16 & 03 & 03 \\
\hline E3 & 07 & 03 & 02 \\
\hline E4 & 02 & 05 & - \\
\hline
\end{tabular}

O quadrante com menor distribuição de membros da rede social foram as relações de conhecidos, sendo composto, por vizinhos e grupos comunitários. E, com relação à composição, membros advindos do trabalho foram os menos citados pelas participantes.

Cabe destacar que alguns membros da rede não foram especificados, sendo utilizados termos generalizáveis como: "sobrinhas", "irmãos", "genros", "amigas", "vizinhos" e, grupos comunitários. Desta forma, os membros da rede são constituídos de números aproximados, não sendo possível obter um número exato de indivíduos que formam a rede social das participantes. O mesmo ocorreu na pesquisa dos autores Leonidas e Santos (2013) na análise dos dados obtidos no Mapa mínimo. Esses achados podem sugerir que talvez haja uma tendência a indicar muitas pessoas na rede, mas, de fato, quando questionadas para nomear estas, as entrevistadas, acabam não conseguindo nomear, individualmente, a todas. Isto pode sugerir, que na verdade, a rede não seja tão grande assim, ou, ainda, nos apontar a necessidade de que sejam realizadas mais entrevistas, para explorar e detalhar o Mapa mínimo, o que em função do tempo de coleta de dados, não se tornou possível.

A composição da rede social das participantes (Tabela 2.) caracterizou-se, principalmente, pela família. Desta forma, observa-se uma grande densidade de membros no mesmo quadrante, pois, percebe-se que existe uma conexão entre os membros citados. Por outro lado, evidencia-se uma baixa dispersão, pois os membros da rede não possuem um grande distanciamento. Além disto, a rede social das quatro participantes se mostrou heterogênea com relação a sua composição, pois, foram citados membros da família, amigos, comunidade, serviços de saúde e religiosos.

Tabela 2 - Composição da rede social de apoio

\begin{tabular}{l|l|l|l|l}
\hline Participantes & Família & Amigos & Comunidade & Trabalho/Estudo \\
\hline E1 & 05 & 03 & 03 & - \\
\hline E2 & 18 & 01 & 02 & - \\
\hline E3 & 09 & - & 03 & - \\
\hline E4 & 05 & 01 & - & 01 \\
\hline
\end{tabular}

Outra pesquisa obteve o mesmo resultado, no qual os integrantes citados como membros da rede social estavam, em sua maioria, situados no primeiro quadrante, das relações íntimas, sendo assim, o apoio ocorria, preferencialmente, com pessoas mais próximas e importantes para o sujeito (Rodrigues \& Ferreira, 2012). Poucas pessoas foram inseridas no círculo das relações sociais e, um número menor ainda no último círculo, dos conhecidos. Além disto, na pesquisa dos autores evidenciou-se que o apoio social era proveniente das relações familiares, ainda que estas fossem marcadas por conflitos (Leonidas \& Santos, 2013).

O quadrante de trabalho/estudo foi o menos citado pelas participantes, sendo citado, apenas, pela entrevistada E4. Este dado pode ser justificado pelo fato de que as participantes E1, E2 e E3 são aposentadas, enquanto E4 ainda trabalha e mantêm vínculos em seu local de trabalho.

\section{Funções da Rede}

A partir da aplicação dos instrumentos foi possível identificar as funções da rede, conforme categorias propostas por Sluzki (1997). Desta forma, a companhia social foi descrita como o principal apoio recebido pelas entrevistadas. Sendo definido como à realização de atividades conjuntas ou simplesmente o 'estar junto', refere-se, portanto, ao acompanhamento que o indivíduo recebe em seu cotidiano (Sluzki, 1997). Isso fica evidenciado quando as entrevistadas citam que durante o tratamento não ficavam sozinhas, tendo companhia de membros de sua rede durante as internações hospitalares e/ou consultas ao médico. Esta função da rede, também, é evidenciada quando as participantes citam pessoas que elas se encontram regularmente ou que elas procuram quando precisam se divertir ou relaxar. O sentimento de 'não estarem sożinhos' contribui para a recuperação dos pacientes oncológicos, fazendo com que eles possam se 
sentir mais confiantes na possibilidade de superação da doença (Conde, Lemos, Pozati \& Ferreira, 2016).

A função guia cognitivo e conselhos refere-se a compartilhar informações pessoais ou sociais (Leonidas \& Santos, 2013). Esta função estava presente nas respostas das participantes, E1 e E3, quando diziam que procuravam alguns membros específicos da rede para poder desabafar, pedir um conselho e/ou contar um segredo. As participantes E2 e E4 afirmaram não receber este tipo de apoio, o que talvez se justifique, tendo em vista que ambas indicaram possuir uma rede social disfuncional, não sendo efetiva no fornecimento de apoio.

O apoio emocional refere-se a um clima de compreensão, simpatia, empatia, estimulo e apoio (Gabarra, 2010), sendo geralmente fornecido pelos membros com quem se estabelece uma relação de maior intimidade. $\mathrm{O}$ apoio emocional foi citado, por exemplo, como uma conversa de incentivo, de apoio e/ou um abraço. As participantes E2 e E4 disseram não receber este tipo de apoio o que, novamente, evidencia que a presença de membros na rede social, não é um indicativo de suporte, pois estes podem não fornecer o apoio suficiente para o bem-estar do indivíduo. Portanto, uma rede frágil de vínculos pode tornar este processo de adoecer mais difícil. Quando o apoio emocional é ineficaz, sintomas depressivos podem ser previstos ao longo do tratamento (Rodrigues, Ferreira \& Caliri, 2013).

Percebe-se no depoimento a seguir, a importância deste apoio emocional: "Palavras boas, assim como eu vou dizer, quando eu tava no começo ainda, eu achava que eu ia morrer sabe. Eu não sei, passou uma coisa na minha cabeça que parecia que en ia morrer. Dai todo mundo vinha conversar, minha irmã, minha filha, meu marido. Todo mundo dizia: Não, vamos em frente" (E1). A partir desse relato, pode-se compreender o apoio emocional como sendo o apoio que envolve o significado de participação dos membros da rede social no tratamento do indivíduo. O que representa uma ajuda, uma motivação, um amparo, um suporte para enfrentar a doença e as suas consequências (Maciel, Lorena, Pereira \& Martins, 2015), proporcionando maior segurança, conforto e solidariedade no decorrer do tratamento (Vestena, Schwartz, Burille, Linck, Lange \& Eslabão, 2012).

A ajuda material e de serviços consiste em ajuda financeira, de informações e de serviços (Sluzki, 1997). Conforme o relato das entrevistadas foi incluído nesta função, o apoio recebido pela equipe médica, pelas instituições, como a secretária de saúde e a prefeitura do município, bem como, o auxílio que receberam de familiares nas atividades cotidianas, como na limpeza da casa. "Eu fui para Caxias com o Dr. $R$ (...) en tava com medo. Dai ele sentou conversou um monte de tempo comigo, dai ele disse que (...) era uma coisa bem fácil, que era bem no começo o meu câncer e que não ia ter problema nenbum, que eu ia ficar bem boa. Dai eu fiquei animada." (E1). "Sabe aquele apoio de precisar ajudar a limpar a casa (...) quem me ajudou muito foi a secretaria aqui, recebi bastante apoio né, se precisava de carro para levar, para buscar" (E3). Não foram citadas pelas participantes desta pesquisa, as funções referentes ao acesso a novos contatos e a regulação social.

\section{Rede social de apoio positiva}

Refere-se a uma rede social com características funcionais, uma rede social efetiva no fornecimento de apoio. Esta se divide em duas subcategorias, sendo elas: a) Antes do diagnóstico e durante o tratamento; b) Atualmente.

\section{Antes do diagnóstico e durante o tratamento}

Esta subcategoria agrupa os depoimentos em que a pessoa sinaliza a presença de uma rede social positiva antes do diagnóstico de câncer e durante todo o tratamento. Neste aspecto, as participantes narraram que a rede social foi facilitadora, para que ocorresse uma melhor aceitação do diagnóstico, bem como, para que o tratamento fosse visto como um processo natural.

Acho que se eu não tivesse a minha filha do meu lado naquela hora, eu não sei o que ia acontecer comigo, mas daí ela me passou tranquilidade (...) minha irmã, minha família, meus irmãos, meu marido em casa sentaram e conversaram comigo (...) eu acho que se eu não tivesse eles, eu acho que eu ia ficar muito deprimida” (E1). “(...) família sim, sim (...) cada dia que eu tinha que ir a Caxias (...) minhas irmãs iam, até mesmo esse marido que eu tenho ele foi junto comigo, os parentes todo mundo (E3).

Evidencia-se pelos depoimentos o quanto as participantes percebem que a rede foi importante, especialmente visto que a participante E1 destaca que se não tivesse a rede, teria se deprimido. A presença de uma rede social de apoio funcional, em pacientes com câncer, aumenta a vontade de viver e a autoestima do indivíduo, o que pode contribuir para o sucesso do tratamento (Andrade \& Vaistman, 2002).

A família, portanto, foi citada pelas participantes, tanto na entrevista como no Mapa mínimo, como sendo a principal fonte de apoio durante o tratamento do câncer. Esse dado corrobora com os achados de outras pesquisas (Gabarra, 2010; Hoffmann, Muller \& Frasson, 2006; 
Leonidas \& Santos, 2013; Primio, Schwartz, Bielemann, Burille, Zillmer \& Feijo, 2010; Sanchez, Ferreira, Dupas \& Costa, 2010; Visona, Prevedello \& Souza, 2012), o que ressalta a preponderância dos vínculos familiares.

Os membros da família constituem-se como fontes de apoio, segurança e estabilidade emocional. A relação entre a rede social de apoio positiva e o tratamento oncológico é diretamente proporcional, pois, quanto mais apoio o paciente recebe, mais positiva será sua reação frente ao diagnóstico e tratamento (Felippe \& Castro, 2015). Tal aspecto foi conceituado como círculos virtuosos, ou seja, a presença da doença fortalece a rede social de apoio e, este fortalecimento ocasiona uma resposta positiva do paciente frente ao tratamento. A melhora na saúde deste paciente, portanto, irá fortalecer, ainda mais, sua rede social de apoio (Sluzki, 1997).

Além da família, outras redes sociais foram apontadas como positivas pelas participantes. Destacando-se pessoas mais distantes em nível de proximidade, como foi o caso da secretaria de saúde do município e de vizinhos:

(...) E meus vizinhos na época também, três deles até, até as últimas três que eu fiz, eles se prontificaram não cobraram um centavo, me levaram e me trouxeram de volta sabe (...) quem me ajudou muito foi a secretaria aqui, recebi bastante de apoio né”(E3).

Outro depoimento aponta para a questão da espiritualidade, ressaltando o quanto esse suporte auxiliou na realização do tratamento:

Eu depositei toda minha confiança em Deus, eu pensei assim, é para ser para mim, ninguém vai tirar isso de mim, se vai ser para mim, então eu vou ter que assumir e seja o que Deus quiser, Deus vai me dar força e ele me deu. Graças a Deus! (E1).

A espiritualidade, portanto, foi citada como um aspecto fundamental para conseguir aceitar o diagnóstico e, para conseguir realizar o tratamento, aceitando o processo de uma maneira menos dolorosa. A fé tem um importante papel no equilíbrio emocional, proporcionando força para que os pacientes continuem lutando (Primio et al., 2010), minimizando o sofrimento causado pelo tratamento (Alves \& Paula, 2016).

Desta forma, percebe-se que a espiritualidade desempenha um papel importante, no sentido de que proporciona um sentimento de apoio, conforto, tranquilidade e esperança. Além disto, a fé representa uma fonte de apoio relacionada à possibilidade, incerta, de morte (Alves \& Paula, 2016). Desse modo, conclui-se que o suporte e o apoio oferecido pelos amigos, familiares e religião, são importantes tanto no diagnóstico e no tratamento, como na reabilitação, no auxílio das necessidades básicas e no desempenho de papéis (Ibiapina et al., 2015).

\section{Atualmente}

Esta subcategoria agrupa os depoimentos em que foi evidenciada a presença de uma rede social de apoio positiva após a realização do tratamento de câncer. Neste aspecto, foi percebido pela participante E1 que o câncer, foi responsável por unir a família, tornando os vínculos das redes sociais mais fortalecidos.

(...) melhorou bastante eu acho. Melhorou mais, a gente é mais assim, mais ah, minha filha sempre foi, meu marido que foi um pouco mais desligado antes, mas agora ele ta, até ta mais ligado depois da doença, do que antes. (E1).

Esse dado vai ao encontro do que propõe alguns autores quando apontam que a doença faz com que as famílias se aproximem, promovendo uma reestruturação familiar (Mathias, Girardon-Perlini, Mistura, Jacobi \& Stamm, 2015; Primio et al., 2010). Contrapondo-se neste aspecto, para uma das entrevistadas não houve mudança significativa em sua rede social após o tratamento, a qual foi percebida como funcional antes do diagnóstico e durante todo o tratamento, mantendo seu caráter de apoio positivo após a realização do tratamento oncológico. “(...) não... tudo igual (...) eu sempre fui uma pessoa assim (...) eu me dou com todo mundo (...) então, a gente ta normal" (E3).

De modo geral, a partir da análise dessa categoria, se percebe que a família foi destacada pelas participantes, como a principal rede social de apoio, antes do diagnóstico de câncer, bem como, durante a realização do tratamento e na fase de manutenção. Porém, outras redes sociais surgiram no relato das entrevistadas como sendo positivas no momento atual de suas vidas, dentre elas, destacam-se os amigos e a participação de grupos comunitários, como por exemplo, a academia do SUS e os grupos de terceira idade promovidos pelo Serviço Social do Comércio (SESC):

(...) quando eu comecei a fazer dai a academia, vai fazer um ano em outubro, (...) eu queria fazer academia né, que era uma coisa que eu gostava de fazer (...)" (E1). "Daí eu me associei no SESC também, então no SESC eu vou, 
agora até, tem as danças assim, e na piscina hidroginástica, e vou muito (E2).

Cada rede social é única e possui sua própria maneira de organização frente à vivência do câncer (Primio et al., 2010). Assim, a repercussão do diagnóstico da doença, causa sentimentos diversos, no paciente e em sua rede social de apoio, o que irá interferir de forma positiva, ou negativa, nestas relações (Mathias et al., 2015). Por esse motivo, a próxima categoria, aborda exemplos de situações inversas, em que a rede social de apoio não foi positiva.

\section{Rede social de apoio negativa}

A categoria rede social de apoio negativa, refere-se a uma rede social de apoio disfuncional, caracterizada por relações conflituosas e insatisfatórias, que acabam não sendo efetivas no fornecimento de apoio. Estas, por sua vez, não conseguem suprir as necessidades do paciente, sejam elas emocionais, cognitivas e/ou materiais. Assim, foram elaboradas duas subcategorias: a) Antes do diagnóstico e durante o tratamento; b) Atualmente.

\section{Antes do diagnóstico e durante o tratamento}

Nesta subcategoria foram agrupadas informações acerca da rede social de apoio negativa antes do diagnóstico do câncer e durante o tratamento. Apesar de citadas como principal fonte de apoio, a família, também, foi apontada, nesta pesquisa, como uma rede social que dificultou o tratamento, bem como, foi vista como negativa antes do diagnóstico.

Além da família, quadrantes de amigos e da comunidade, também, foram apontados como negativos pelas participantes. A rede social de apoio negativa foi responsável por tornar o momento do diagnóstico, bem como, a aceitação ao tratamento, um processo mais difícil para as participantes.

É, meu marido, ele é assim muito violento assim, eu apanhava muito uma vez. E justamente naquela vez que eu ganhei o câncer, ele me deu um tapa nos seios, e nós tudo, achava que não era, mas eu ainda até hoje não garanto que não foi mesmo por causa do tapa (...), mas eu sofri muito, sofri muito com ele (...) a minha vida, foi assim, uma bagunça” (E2). “(...) não tive muito apoio, não tive muita gente assim, sabe só do meu falecido marido (...), mas assim de amigos, parentes, foi muito pouco (...) porque se fosse pelos meus filhos, pelo meu ex-marido, ou pela minha família, irmãos, enfim... eu não tinha sobrevivido não (...) (E4).
Assim, percebe-se que nem sempre os familiares apresentam uma estrutura adequada para enfrentar todas as demandas que a situação de doença requer, desta forma, o processo de adoecimento de um familiar pode contribuir para a instalação de uma crise no núcleo familiar (Visona, Prevedello \& Souza, 2012). Isso fica evidenciado, quando a participante E2 levanta a possibilidade de que a doença tenha se instaurado por causa de 'um tapa' que levou do marido. Deste modo, a doença pode tornar mais rígida uma disfunção familiar pré-existente (Rolland, 1995).

A doença, portanto, pode ocasionar, ou maximizar, problemas de relacionamentos entre casais, entre pais e filhos, entre outros familiares, entre amigos e entre a comunidade (Primio et al., 2010). Em outra pesquisa, alguns participantes narraram sentir a falta do apoio de seus familiares, amigos e do serviço de saúde (Gabarra, 2010). A autora supracitada apresenta que estas redes reduzidas ou ineficazes dificultaram a adaptação psicossocial dos pacientes e favoreceram o desenvolvimento de transtornos depressivos e de ansiedade.

\section{Atualmente}

Esta subcategoria refere-se à presença de uma rede social negativa no momento atual de vida das participantes, ou seja, no momento do pós-tratamento. Foi possível perceber que redes consideradas como negativas, antes do diagnóstico e/ou durante o tratamento, se mantiveram desse modo após a realização do tratamento. Desta forma, apesar das entrevistadas possuírem uma rede social de apoio, evidencia-se que a mesma é escassa de vínculos, pois as participantes não recebem apoio de seus integrantes.

Agora eu vivo muito sozinha (...) é que agora eu moro só com o marido ainda, as filhas tão tudo casada, to sozinha agora com o marido (...)" (E2). “(...) nossa, mudaram muito... mudaram muito no modo de se afastarem sabe, porque eu tinha muitas amigas, eu tinha muitos amigos, eu tinha... assim, entre aspas, porque hoje eu digo que não são, porque quando descobriram, tem amigas que logo que descobriram que eu fiz cirurgia nunca me ligaram e nem me visitaram para saber como eu tava (...) (E4).

A pobreza de relações sociais é visto como fator de risco a saúde quando comparado com outros fatores que são comprovadamente nocivos, como o fumo, a pressão arterial elevada, a obesidade e a ausência de atividade física. Para tanto, os relacionamentos problemáticos ou 
superficiais muitas vezes não resistem, sendo excluídos do convívio familiar e às vezes tornam-se prejudiciais do ponto de vista emocional (Andrade \& Vaistman, 2002). Com relação ao cônjuge, o câncer influencia os relacionamentos já abalados anteriormente, havendo uma desestruturação ainda maior destas relações (Salci \& Marcon, 2011).

\section{Mudanças após o tratamento}

A categoria, mudanças após o tratamento, diz respeito às mudanças que as entrevistadas apontaram que ocorreram nas suas vidas após o tratamento para o câncer. Esta categoria está dividida em três subcategorias: a) Alterações físicas; b) Alterações emocionais; c) Alterações financeiras.

\section{Alterações físicas}

Esta subcategoria corresponde as alterações físicas que ocorreram nas participantes após o tratamento de câncer. Assim, foram incluídas as mudanças ocasionadas pelos efeitos colaterais do tratamento, por exemplo: perda de cabelo, emagrecimento e dificuldade na alimentação.

A única coisa que me atrapalha é (...) eu não consigo engordar sabe, eu to no último grau de desnutrição, então é a única coisa que me abala, que me atrapalha muito desde a cirurgia (E4).

O impacto ocasionado pelo diagnóstico de câncer e as consequências dos tratamentos podem alterar a capacidade funcional dos pacientes, comprometendo o desempenho ocupacional, dificultando a realização das atividades cotidianas e provocando importantes alterações na qualidade de vida desses indivíduos (Ribeiro, Schwartz, Feijo, Santos, Garciz, \& Lise, 2015).

\section{Alterações emocionais}

Esta subcategoria refere-se às mudanças emocionais percebidas pelas participantes após o tratamento. Foram relatadas questões sobre isolamento, medo de metástase, tristeza e felicidade. Neste sentido, foi possível perceber que as entrevistadas com uma rede social disfuncional foram as que narraram questões sobre se sentirem sozinhas e tristes (E2, E4).

(...) porque eu vi que me isola do jeito que eu me isolava não era o caminho, eu estava pensando nossa eu vou morrer aqui nesse quarto ninguém vai ver, porque ninguém aparece sabe, mas enfim (...) (E4).
Diante desses achados, pode-se inferir que a falta de uma rede de apoio funcional poderia predispor problemas de ordem emocional. Pois, pacientes com câncer que se encontram no pós-tratamento possuem uma maior prevalência de desenvolver depressão (Ferreira, Oda, Duarte, Machado \& Bicalho, 2015). Para os pesquisadores citados esta prevalência se justifica pelas grandes alterações psicológicas causadas pelo adoecimento do câncer e pelas modificações físicas provenientes dos tratamentos.

Por outro lado, a participante E1, a qual possui uma rede social de apoio funcional relatou mudanças positivas em sua vida após o tratamento. "Eu sou feliz! Eu aprendi muita coisa depois da cirurgia, eu sou outra pessoa, mais alegre" (E1). A vivencia do câncer pode promover uma re-significação dos valores pessoais, como se esta experiência apontasse para novos modos de vida e redefinição de prioridades (Cano, 2014).

\section{Alterações financeiras}

Esta subcategoria é caracterizada pelas mudanças percebidas nos aspectos financeiros. A participante E4 relatou estar enfrentando dificuldades financeiras, devido ao fato de 'ser sozinha'. Está falta de apoio pode estar relacionada, e/ou ser uma consequência negativa de redes sociais disfuncionais. Portanto, mesmo sendo apenas a evidencia de uma participante, torna-se importante destacar que ela aponta que essa dificuldade se deve a sua escassez de apoio:

E a dificuldade né, a situação financeira né, sozinha, com aluguel, água, luz, comida (...) Dai tem os filhos, mas são todos casados, eles também têm a família deles, eles também não tem condição de ficar me ajudando. Eles nunca me perguntaram, mãe tu precisa de algum remédio? Mãe, tu precisa de alguma coisa sabe? E daí eu não quero tá pedindo, tá dizendo a minha dificuldade pra eles, entende? Então, eu carrego muito peso comigo (...) (E4).

Na pesquisa de Ribeiro et al. (2015) um participante, também, referiu-se, como um incidente negativo, do pós-tratamento, a necessidade de retornar ao trabalho devido às dificuldades financeiras que apareceram com o tratamento. Por outro lado, o restante das participantes, da pesquisa dos autores acima, bem como, desta pesquisa, relataram que a situação financeira não foi significativamente atingida pela doença.

Diante dos resultados expostos é possível perceber que o diagnóstico, o tratamento, bem como, a fase do pós-tratamento do câncer causam diversas repercussões 
na vida das pessoas envolvidas, podendo modificar a dinâmica e o contexto de vida do paciente e de toda a sua rede social (Mathias et al., 2015). Entende-se que no momento que os profissionais da saúde conhecem mais sobre as peculiaridades que envolvem o tratamento oncológico, será possível aperfeiçoar as práticas de cuidado (Ribeiro et al., 2015).

Cabe ao serviço, e aos profissionais de saúde, portanto, uma atuação que entenda os pacientes com câncer em seu aspecto biopsicossocial espiritual (Hoffmann, Muller \& Frasson, 2006), especialmente nas diferentes fases da doença, ou seja, antes, durante e após o tratamento. Pois, deste modo, pode-se ampliar o suporte, diminuir a sensação de isolamento e proporcionar aos pacientes, uma melhor compreensão de seus sentimentos e emoções (Monte et al. 2015).

\section{Considerações Finais}

A presença de uma rede social funcional é fundamental para o bem-estar de todos os indivíduos, especificamente, em pacientes com câncer. A pesquisa mostrou que uma rede social fornecedora de apoio em situações de crise, melhora a autoestima e a qualidade de vida desses pacientes, tornando o diagnóstico, o tratamento e, o pós-tratamento um processo menos doloroso. Assim, destaca-se que as redes sociais com bons vínculos conseguiram manter este padrão positivo após o tratamento e, em alguns casos, os vínculos foram fortalecidos e os relacionamentos foram citados como melhores após o diagnóstico.

Além disto, os dados também apontam que redes sociais com características disfuncionais, tornam o processo mais difícil, e, na maioria dos casos, estes mantêm o padrão disfuncional, durante todas as fases do tratamento. Portanto, o sujeito pode participar de uma rede social de apoio e não receber apoio efetivo.

Entre os achados da pesquisa, convém ressaltar que a composição da rede social das participantes caracterizou-se predominantemente por pessoas da família. Nessa mesma linha, a principal função exercida pela rede, foi apontada como a companhia social, o estar junto, a convivência e a presença nas tarefas cotidianas.

Cabe apontar um limite da pesquisa que foi o número reduzido da amostra. Além disto, entende-se, também, como limitações desta, o fato das participantes serem todas mulheres, de modo que se sugere a realização de novas pesquisas com um número maior de participante e a inclusão de homens. Entre as possibilidades de novas pesquisas, poderiam ser aprofundados os conhecimentos das redes dos pacientes, nas diferentes fases do tratamento, assim como pesquisas incluindo os membros da rede destes pacientes, para que se amplie o ponto de compreensão.

Diante do exposto, e ao considerar a incidência da doença, que é vista, atualmente, como um problema de saúde pública, mostra-se relevante o desenvolvimento de estudos sobre a temática do câncer em todas as áreas da saúde, a fim de melhorar o tratamento ao paciente e a sua família. Especialmente, pois, o conhecimento sobre a temática das redes sociais favorece ações de promoção e prevenção da saúde, que por sua vez, podem repercutir positivamente, no impacto causado pela doença.

\section{Referências}

Alves, J. P. S., \& Paula, M. F. C. (2016). A espiritualidade na arte do cuidar: experiência do idoso hospitalizado com câncer. CLAIQ2016, 2, p.276-285. Recuperado de http://proceedings.ciaiq.org/index.php/ciaiq2016/article/ view/762.

Andrade, G., \& Vaistman, J. (2002). Apoio social e redes: conectando solidariedade e saúde. Ciência \& saúde coletiva, Rio de Janeiro, 7(4). p.925-934. Recuperado de http://www.scielo.br/pdf/csc/v7n4/14615.pdf.

Borges-Osório, M. R., \& Robinson, W. M. (2002). Genética bumana (2 $2^{\mathrm{a}} \mathrm{ed}$.) Porto Alegre: Artmed.

Bottino, S. M. B., Fraguas, R., \& Gattaz, W. F. (2009). Depressão e câncer. Rev. psiquiatr. clín., São Paulo, 36(3), p.109-115. DOI: http://dx.doi.org/10.1590/ S0101-60832009000900007

Cano, D. S. (2014) O médico entre a vida e a morte: um estudo psicológico em oncologia clínica. São Paulo: Casa do Psicólogo.

Cavini, J. M. T. G., \& Gaspar, K. C. (2013). Dilemas emocionais dos familiares de pacientes com câncer. In Angerami-Camon, V. A., \& Gaspar, K. C. (Orgs.). Psicologia e câncer (pp.223-243). São Paulo: Casa do Psicólogo.

Conde, C. R., Lemos, T. M. R., Pozati, M. P. S., \& Ferreira, M. L. S. M. (2016). A repercussão do diagnóstico e tratamento do câncer de mama no contexto familiar. CIAIQ2016, 2, p. 1544-1553. Recuperado de http://proceedings. ciaiq.org/index.php/ciaiq2016/article/view/913.

Conselho Federal de Psicologia. (2000). Resolução nº 016/2000. Recuperado de http://www.crprs.org.br/upload/legislacao/legislacao68.pdf.

Conselho Nacional de Saúde. (2016). Resolução nº 510/2016. Recuperado de http://conselho.saude.gov.br/resolucoes/2016/Reso510.pdf.

Creswell, J. W. (2010). Projeto de pesquisa: métodos qualitativos, quantitativo e misto. (3.ed.). Porto Alegre: Artmed.

Elmescany, E. N. M. (2010). A arte na promoção da resiliência: um caminho de intervenção terapêutica ocupacional na atenção oncológica. Revista do Nufen, 1(2), p.21-41. Recuperado de http://pepsic.bvsalud.org/pdf/rnufen/ v2n2/a03.pdf.

Felippe, T. C. A., \& Castro, P. F. (2015). Percepção sobre diagnóstico e tratamento em pacientes oncológicos. Revista Saúde UNG, 9(1-2), p.4-20. Recuperado de http://revistas.ung.br/index.php/saude/article/view/1933.

Ferreira, A. S., Oda, J. M. M., Duarte, S. J. H, Machado, R. M., \& Bicalho, B. P. (2015). Câncer de mama: estimativa da prevalência de ansiedade e depressão em pacientes em tratamento ambulatorial. Arq. Ciênc. Saúde UNIPAR, Umuarama, 19(3), p.185- 189. Recuperado de http://bases.bireme.br/cgi-bin/wxislind.exe/iah/online/?IsisScript $=$ iah/iah.xis\&src $=$ google\&base $=\mathrm{L}$ ILACS\&lang $=$ p\&nextAction $=\ln k \&$ exprSearch $=784426 \&$ indexSearch=ID.

Gabarra, L. M. (2010). Estados emocionais, formas de enfrentamento, rede de apoio e adaptação psicossocial em pacientes amputados. (Tese de doutorado, Universidade Federal de Santa Catarina, Centro de Filosofia e Ciências Humanas, Florianópolis) Recuperado de https://repositorio.ufsc.br/ handle/123456789/93889.

Hoffmann, F. S., Muller, M. C., \& Frasson, A. L. (2006). Repercussões psicossociais, apoio social e bem-estar espiritual em mulheres com câncer de mama. Psic., Saúde \& Doenças, Lisboa, 7(2), p.239-254. Recuperado 
de http:/ / www.scielo.mec.pt/scielo.php?script=sci_arttext\&pid=S1645$-00862006000200007 \& \operatorname{lng}=$ pt\&nrm $=$ iso.

Ibiapina, R. S., Maia, J. M., Silva, L. D. C., Fernandes, M. A., Filho, A. A. I. C., \& Fernandes, R. O. (2015). Aspectos psicoemocionais de mulheres pós-Mastectomizadas participantes de um grupo de apoio de um hospital geral. Revista Interdisciplinar, 8(3), p.135-142. Recuperado de http://revistainterdisciplinar.uninovafapi.edu.br/index.php/revinter/article/view/775.

INCA - Instituto Nacional de Câncer José Alencar Gomes da Silva. (2015). O que é o câncer? INCA, Ministério da Saúde, Rio de Janeiro. Recuperado de http://www1.inca.gov.br/conteudo_view.asp?id=322.

Lacerda, A. (2010). Redes de apoio social no sistema da dádiva: um novo olhar sobre a integralidade do cuidado no cotidiano de trabalho do agente comunitário de saúde. (Tese de doutorado, Escola Nacional de Saúde Pública Sergio Arouca, Rio de Janeiro). Recuperado de http://bases.bireme.br/cgi-bin/ wxislind.exe/iah/online/?IsisScript=iah/iah. xis\&src $=$ google\&base $=$ LIL

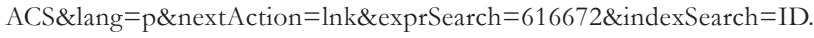

Laville, C., \& Dionne, J. (1999). A construção do saber: manual de metodologia da pesquisa em ciências humanas. Porto Alegre: Artmed.

Leonidas, C. (2012). Redes sociais e apoio social no contexto dos transtornos alimentares. (Dissertação de Mestrado, Universidade de São Paulo, Ribeirão Preto). Recuperado de http://www.ffclrp.usp.br/imagens_defesas/17_12_2012_11_16_29_61.pdf.

Leonidas, C., \& Santos, M. A. (2013). Redes sociais significativas de mulheres com transtornos alimentares. Psicologia: Reflexão e Crítica, Ribeirão Preto, 26(3), p.561-571. Recuperado de http://www.scielo.br/pdf/prc/v26n3/ v26n3a16.

Maciel, A. F., Lorena, J. C., Pereira, M. I. M., \& Martins, R. C. (2015). Paciente com câncer: significado da família no seu tratamento. Enfermagem Brasil, 14(4), p.195-201. Recuperado de http://www.portalatlanticaeditora.com. br/index.php/enfermagembrasil/article/view/41.

Marconi, M. A., \& Lakatos, E. M. (2009). Fundamentos da metodologia científica. ( $6^{a}$ ed.) São Paulo: Atlas.

Mathias, C. V., Girardon-Perlini, N. M. O., Mistura, C., Jacobi, C. S., \& Stamm, B. (2015). O adoecimento de adultos por câncer e a repercussão na família: uma revisão da Literatura. Revista de Atenção à Saúde, 13(45), p.80-86. DOI: $10.13037 /$ ras.vol13n45.2818.

Menezes, M., Moré, C., \& Barros, L. (2015). Redes sociais significativas de familiares acompanhantes de crianças hospitalizadas. In Congresso Íbero Americano em investigação qualitativa - CIAIQ2015, Aracaju, 1. Recuperado de http://proceedings.ciaiq.org/index.php/ciaiq2015/article/view/126.

Monte, L. R. S., Soares, T. R., Portela, N. L. C., Pedrosa, A. O., Gomes, R. N. S., \& Filho, R. L. (2015). Avaliação dos níveis de depressão identificados em mulheres com diagnóstico de câncer de mama. Revista Interdisciplinar,
8(4), p.64-70. Recuperado de http://revistainterdisciplinar.uninovafapi.edu. br/index.php/revinter/article/view/684.

Primio, A. O., Schwartz, E., Bielemann, V. L. M., Burille, A., Zillmer, J. G. V., \& Feijo, A. M. (2010). Rede social e vínculos apoiadores das famílias de crianças com câncer. Texto \& contexto enferm., 19(2), p.334-42. DOI: http:// dx.doi.org/10.1590/S0104-07072010000200015.

Ribeiro, S. L., Schwartz, E., Feijo, A. M., Santos, B. P., Garciz, R. P., \& Lise, F. (2015). Incidentes críticos experienciados no tratamento da doença oncológica. R. Enferm. Cent. O. Mind, 5(3), p.1805-1819. DOI: http://dx.doi. org/10.19175/recom.v5i3.898.

Rodrigues, J. S. M., \& Ferreira, N. M. L. A. (2012). Estrutura e funcionalidade da rede de apoio social do adulto com câncer. Acta Paul Enferm, 25(5), p.781-787. Recuperado de http://www.scielo.br/pdf/ape/v25n5/21.pdf.

Rodrigues, J. S. M., Ferreira, N. M. L. A., \& Caliri, M. H. L. (2013). Caracterização do apoio social percebido pela família do doente adulto com câncer. Medicina, Ribeirão Preto, 46(3), p.289-296. DOI: http://dx.doi. org/10.11606/issn.2176-7262.v46i3p289-296.

Rolland, J. S. (1995). Doença crônica e o ciclo de vida familiar. In Carter, B., \& Mcgoldrick, M. (Orgs.). As mudanças no ciclo de vida familiar. (2 ${ }^{\mathrm{a}} \mathrm{ed}$.). Porto Alegre: Artmed.

Salci, M. A., \& Marcon, S. S. (2011). Enfrentamento do câncer em família. Texto \& Contexto - Enfermagem, Florianópolis, 20 (spe), p.178-186. DOI: https://dx.doi.org/10.1590/S0104-07072011000500023

Sanchez, K. O. L., Ferreira, N. M. L. A., Dupas, G., \& Costa, D. B. (2010). Apoio social à família do paciente com câncer: identificando caminhos e direções. Revista brasileira de enfermagem, Brasília, 63(2), p.290-299. Recuperado de http://www.redalyc.org/pdf/2670/267019594019.pdf.

Santana, J. J. R. A., Zanin, C. R., \& Maniglia, J. V. (2008). Pacientes com câncer: enfrentamento, rede social e apoio social. Paidéia, 18(40), p.371-384. Recuperado de http://www.scielo.br/pdf/paideia/v18n40/13.pdf.

Sluzki, C. E. (1997). A rede social na prática sistêmica. São Paulo: Casa do Psicólogo.

Vestena-Zilmer, J.G., Schwartz, E., Burille, A., Linck, C.L., Lange, C., \& Eslabão, A. (2012). Vínculos dos clientes oncológicos e familiares: uma dimensão a ser conhecida. Enfermeria Global, 11(1), p.45-52. Recuperado de http://scielo.isciii.es/pdf/eg/v11n25/pt_clinica3.pdf.

Visona, F., Prevedello, M., \& Souza, E. N. (2012). Câncer na família: percepções de familiares. Revista de Enfermagem da UFSM, 2(1). p.145-155. Recuperado de http://cascavel.cpd.ufsm.br/revistas/ojs-2.2.2/index.php/reufsm/ article/view/3943/3148.

Submetido em: 28-4-2018

Aceito em: 8-7-2018 